\title{
SPENT NUCLEAR FUEL TRANSPORTATION: AN EXAMINATION OF POTENTIAL LESSONS LEARNED FROM PRIOR SHIPPING CAMPAIGNS
}

\author{
Marsha Keister \\ Kathryn McBride
}

August 2006

The INL is a U.S. Department of Energy National Laboratory operated by Battelle Energy Alliance 
INL/EXT-06-11223

\title{
SPENT NUCLEAR FUEL TRANSPORTATION: AN EXAMINATION OF POTENTIAL LESSONS LEARNED FROM PRIOR SHIPPING CAMPAIGNS
}

\author{
Marsha Keister \\ Kathryn McBride
}

August 2006

Idaho National Laboratory

Idaho Falls, Idaho 83415

Prepared for the

U.S. Department of Energy

Office of Civilian Radioactive Waste Management

Office of National Transportation

Under DOE Idaho Operations Office

Contract DE-AC07-05ID14517 


\section{INTRODUCTION}

The Nuclear Waste Policy Act of 1982 (NWPA), as amended, assigned the Department of Energy (DOE) responsibility for developing and managing a Federal system for the disposal of spent nuclear fuel (SNF) and high-level radioactive waste (HLW). The Office of Civilian Radioactive Waste Management (OCRWM) is responsible for accepting, transporting, and disposing of SNF and HLW at the Yucca Mountain repository (if licensed) in a manner that protects public health, safety, and the environment; enhances national and energy security; and merits public confidence.

OCRWM faces a near-term challenge-to develop and demonstrate a transportation system that will sustain safe and efficient shipments of SNF and HLW to a repository. To better inform and improve its current planning, OCRWM has extensively reviewed plans and other documents related to past high-visibility shipping campaigns of SNF and other radioactive materials within the United States. This report summarizes the results of this review and, where appropriate, lessons learned.

\section{OBJECTIVE OF THE STUDY}

The objective of this lessons learned study was to identify successful, best-in-class trends and commonalities from past shipping campaigns, which OCRWM could consider when planning for the development and operation of a repository transportation system. Note: this paper is for analytical and discussion purposes only, and is not an endorsement of, or commitment by, OCRWM to follow any of the comments or trends. If OCRWM elects to make such commitments at a future time, they will be appropriately documented in formal programmatic policy statements, plans and procedures.

Reviewers examined an extensive study completed in 2003 by DOE's National Transportation Program (NTP), Office of Environmental Management (EM), as well as plans and documents related to SNF shipments since issuance of the NTP report. OCRWM examined specific planning, business, institutional and operating practices that have been identified by DOE, its transportation contractors, and stakeholders as important issues that arise repeatedly. In addition, the review identifies lessons learned or activities/actions which were found not to be productive to the planning and conduct of SNF shipments (i.e., negative impacts).

This paper is a "looking back" summary of lessons learned across multiple transportation campaigns. Not all lessons learned are captured here, and participants in some of the campaigns have divergent opinions and perspectives about which lessons are most critical. This analysis is part of a larger OCRWM benchmarking effort to identify best practices to consider in future transportation of radioactive materials ("looking forward"). Initial findings from this comprehensive benchmarking analysis are expected to be available in late fall 2006.

For further information regarding OCRWM's benchmarking project, please contact Alex Thrower, DOE/OCRWM, at (202) 586-7905 or via email: alexander.thrower@rw.doe.gov. 


\section{SCOPE OF THE REVIEW}

Transportation of SNF and HLW is a complex undertaking, involving different regulatory regimes, logistical considerations and contingency planning. DOE's Radioactive Material Transportation Practices Manual, DOE M 460.2-1, contains 14 different practices (see Table 1) meant to coincide with roughly sequential planning steps, beginning with transportation planning and ending with emergency cleanup and recovery. The Practices Manual covers all radioactive material shipments undertaken by or for the Department of Energy (excluding air and barge shipments and certain national security shipments). Most of the campaigns studied were conducted using the practices and guidance in DOE M 460.2-1.

Table 1: Transportation Practices Listed in DOE M 460.2-1

1. Transportation Planning

2. Emergency Planning

3. Projected Shipment Planning Information

4. Routing

5. Security

6. Carrier/Driver Requirements

7. Shipment Prenotification

8. Transportation Operational Contingencies

9. Tracking

10. Inspections

11. Safe Parking

12. Emergency Notification

13. Emergency Response

14. Recovery and Cleanup

Although every aspect of planning and operations is important, for purposes of this review OCRWM concentrated on three sub-topics for more detailed study. These topics were selected because, while OCRWM shipments may not occur for some years, advance planning and decision-making in these areas is happening now, and the transportation program could thus benefit significantly from this analysis in the near term. The three sub-topics examined were:

1. Transportation Business Model - how the logistics functions developed, how they are organized, and what factors influence their performance;

2. Outsourcing - how decisions about logistics outsourcing were made, and how high performance is maintained;

3. Stakeholder Relations-how was trust and confidence in the transportation system built, and how have stakeholder interactions evolved over time. 


\section{DOCUMENTS REVIEWED}

The following lists the shipping campaign plans, lessons-learned or other documents which were reviewed as part of this study.

1. Best Practices and Findings for DOE Programs Transporting Spent Nuclear Fuel; Final January 2003; prepared by Science Applications International Corporation Energy Solutions Group for the U. S. DOE. This paper benchmarks the Radioactive Material Transportation Practices Manual (2002) against pre-2003 transportation plans and guides for rail and highway shipping campaigns in terms of specific planning and programmatic activities for the shipping of radioactive waste. Twelve overall planning processes and transportation plans were reviewed and compared against the practices.

2. West Valley Spent Nuclear Fuel Shipment Project Lessons Learned; April 2004 and November 2001. On July 17, 2003, the U.S. DOE completed the movement of 125 commercial SNF assemblies from the West Valley Demonstration Project to the Idaho National Engineering and Environmental Laboratory (INEEL). The assemblies were transported by rail in two dual-purpose shipping and storage casks and moved 2300 miles; the shipment arrived ahead of schedule and without incident. Planning, preparation and conduct involved four railroads, eleven States, two Tribes and five Federal Railroad Administration regions. Input for this document was received from staff in the involved railroads, States, Tribes, and the Federal Railroad Administration plus DOE and contractor staff.

3. Lessons Learned Cross Country Transportation Working Group. This document identifies lessons learned during the June 2001 truck shipment of U.S. DOE Foreign Research Reactor Spent Nuclear Fuel from the Savannah River Site (SRS) to INEEL.

4. Transportation External Coordination Working Group (TEC) Meeting Summaries. At the July 2000 TEC meeting, over 110 participants representing State, Tribal and local governments, regional groups, industry and professional organizations, DOE, and other Federal agencies met to discuss a variety of issues related to DOE's radioactive materials transportation activities. A subsequent meeting in July 2003 specifically explored best practices and lessons learned from business and industry and DOE shipments in order to improve DOE shipment practices in the future. Similar discussions were held at the September 2004 TEC meeting.

5. Foreign Research Reactor West Coast Shipment Spent Nuclear Fuel Transportation External Lessons Learned, October 1998. In July 1998, Training, Research, Isotope, General Atomics (TRIGA) SNF was received from South Korea at the Concord Naval Weapons Station in California and shipped by rail to the INEEL. The shipment arrived without incident. This document was prepared with input from key stakeholders from State, local and Tribal agencies from the four corridor states.

6. Waste Isolation Pilot Plant. Various presentations, papers and documents provided by WIPP staff prior to and during a December 2005 OCRWM benchmarking trip to WIPP 
address various topics, including the WIPP RCRA recertification application, site overviews and program updates, evolution of the WIPP transportation program, stakeholder communications and public collaborations. Staff also reviewed the WIPP Transportation Safety Program Implementation Guide, Dec. 2003, published by the Western Governors' Association.

\section{SUMMARY OF FINDINGS}

The following summarizes lessons-learned findings which were common across multiple transportation campaigns, or those findings which may have unique applicability to future OCRWM shipments. Appendix A contains a bulletized list of campaign-specific findings.

\section{TRANSPORTATION BUSINESS MODEL/TRANSPORTATION PLANNING}

The way in which DOE programs planned and organized shipping campaigns was a central focus of discussion and debate, both before and after shipments occurred. Commenters almost unanimously observed that DOE has a responsibility to ensure there is frequent and consistent communication and coordination among all parties involved; that DOE should share information with all agencies helping to plan and execute the shipments; and that DOE should have a systematic method of communications among predesignated points-of-contact from every involved entity. Keeping points- of -contact lists current, including points- of- contact for states and tribes, is one labor-intensive but critical administrative task that can be readily addressed with systematic communication. In some cases, problematic issues arose simply because a list had an inaccurate telephone listing, such as when someone had retired.

DOE programs received consistently positive results from holding operational readiness reviews with owners, shippers, receiving sites, transportation contractors, and corridor States and Tribes. These reviews are used to obtain confirmation that each participant is ready, that unresolved issues have been identified and addressed, and that review of all shipping documents has been completed.

Based on the experiences of the various campaigns examined, it appears DOE managers have benefited from applying a "prudent business standard", going beyond specific regulatory requirements. By doing so, successful managers have increased stakeholder confidence, avoided potential conflict with States and reduced project risks (i.e., avoided delays). DOE programs work with a broad range of stakeholders and may receive numerous requests related to transportation plans-such as taking (or avoiding) specific routes, avoiding congested areas at certain times of day, or using nonstandard equipment. Managers and planners must determine whether agreeing to such requests is reasonable, taking into account such factors as (1) cost and practicality; (2) actual versus perceived risks, or benefits to safety; and (3) whether a given action will set a precedent for future shipments, or contravene past ones. Campaign credibility can be undermined if management commits to additional steps that add substantial cost without actually enhancing safety. On the other hand, a blanket policy to reject any "above-regulatory" request, no matter how minor, may not be reasonable and could itself jeopardize mission success. 
Regarding the specifics of the planning documents themselves, programs tended to follow a standard format with elements described in the DOE M 460.2-1, Radioactive Material Transportation Practices Manual" (see Table 2). Before this manual was issued in September 2002, other documents, such as the DOE Program Managers Guide to Transportation Planning, also listed similar plan components. Programs generally had a higher-level campaign plan that was circulated broadly, with more specific topical plans (security, emergency response, inspections, communications) having more limited circulation.

\section{Table 2: Typical Elements of DOE Transportation Plans}

1. Organizational roles and responsibilities

2. Material to be shipped

3. Projected shipping window

4. Estimated number of shipments

5. Mode of transport and carriers to be used

6. Packages to be used

7. Preferred and/or alternative routes

8. Shipment prenotification

9. Safe parking arrangements

10. Tracking systems

11. Emergency preparedness and response

12. Recovery and cleanup

13. Security arrangements

14. Public Information

Source: DOE M 460.2-1, 2.2.5, "Transportation Plans"

For routing issues, programs appeared to benefit by defining a standard approach in identifying routes, and then sticking to the plan. Successful programs involved early process coordination and discussion with corridor States and Tribes, even if the specific route to be used could not be finalized until the shipment date is near. The issue of safety and radiological inspections was a common concern, especially in the context of rail operations. Inspections were often logistically difficult to arrange when schedules changed or there were multiple inspections over a long routeSome programs noted that if rigorous inspections at origin and destination points were conducted, and the results showed consistently high levels of performance, the numbers of inspections might be reduced. This issue remains a critical one for corridor States, some of which require enroute inspections.

Security continues to be a major concern voiced by all parties involved. Shipment participants consistently indicated the need to balance need-to-know security limitations with the need for coordination of information. DOE also should ensure all involved parties understand requirements for safeguarding information appropriately. Security policies and practices need to be consistent. Some participants did not always observe established security procedures (such as leaving sensitive information on answering machines). If State police escorts are used for shipments, careful planning is needed to schedule "hand-offs" at State borders for truck shipments. Some observers urged use of Federal escorts. 


\section{OUTSOURCING}

Campaign participants stressed repeatedly good contract performance requires clarity of terms and expectations between the DOE customer and the transportation services provider. Other parties such as States may be interested in aspects of this relationship, but they should not be interposed between contracting parties because of the potential for confusion or misdirection regarding key terms of contract performance and liability. Using checklists as living documents to identify responsibilities and to status activities has proven to be valuable. The rail environment has unique operating considerations that were not often well understood, which sometimes led to confusion, unrealistic expectations or costly changes to plans. One contributor urged DOE to develop system-wide tenders rather than contracts with each railroad, which sometimes proved cumbersome. Finally, several participants noted that DOE programs frequently underestimated how long it would take to complete service negotiations, which can lead to schedule slippage, delays and added cost and inconvenience.

\section{STAKEHOLDER RELATIONS}

Accurate and clear communication with stakeholders was identified by every program as a critically important aspect of success. Such efforts worked especially well when tied into a robust training program. Most DOE transportation programs supported emergency response training in one form or another. Responder training has obvious benefits in preparing communities for shipments, but the training process has important additional benefits as well. Good, comprehensive and meaningful responder training can serve to "tie" together other campaign planning needs. The Office of Environmental Management's (EM's) Transportation Emergency Preparedness Program (TEPP) uses a modular approach to prepare responders, which can easily be integrated into existing State and Tribal training programs. Part of that training includes public information and education materials, and because local law enforcement and response personnel are highly trusted by their constituents they can provide important information at a grassroots level about transportation plans and procedures. Also, realistic exercises help shippers, carriers, States and Tribes work through how shipments occur and unusual events develop, and may themselves be positive news events in a local community.

Programs often found it helpful to develop and provide resource guides and media packets that focused on material-specific information, not campaign-specific information. Basic information about radioactive materials transportation has been developed, and shipping programs should use those materials to maintain a consistent and accurate stream of information. Programs should work closely with States and Tribes to ensure all information products are accurate and useful. 


\section{APPENDIX A \\ LESSONS LEARNED FROM \\ CRITICAL BUSINESS PROCESSES FOR THE NATIONAL TRANSPORTATION \\ SYSTEM}

\section{REFERENCE KEY:}

1. SNF - Best Practices and Findings for DOE Programs Transporting Spent Nuclear Fuel; Final January 2003; Prepared by Science Applications International Corporation Energy Solutions Group for the U. S. DOE

2. WVSNF - West Valley Spent Nuclear Fuel Shipment Project Lessons Learned; April 2004 and November 2001

3. CCTWG - Lessons Learned Cross Country Transportation Working Group (June 2001 shipment)

4. TEC - Transportation External Coordination Working Group (TEC) meeting summaries;

a. TEC 1 - July 2000 TEC meeting

b. TEC 2 - July 2003 TEC meeting

c. TEC 3 - September 2004 TEC meeting

5. FRR - Foreign Research Reactor West Coast Shipment Spent Nuclear Fuel Transportation External Lessons Learned, October 1998

6. WIPP - Waste Isolation Pilot Plant (various documents)

\section{TRANSPORTATION BUSINESS MODEL}

\section{Transportation Planning}

- Use best practices \& lessons learned from past shipping campaigns - domestic, international \& industry (TEC 2).

- Strive for more consistent, centralized planning by gaining consistency among DOE's programs before consulting with States, Tribes, stakeholders, etc. (TEC 2; WIPP).

- Freely share information with other agencies and organizations that are helping to plan the shipments (SNF; WIPP).

- Hold an operational readiness review to include material owner, shipper, receiving site, transportation contractors, States and Tribes, and others involved in the shipment to ensure concurrence from each participant that they are ready, that unresolved issues have been identified and addressed, and that review of all shipping documents has been completed, etc. (WVSNF).

- Need enhanced, ongoing, open communication prior to planning logistics (TEC 2; WIPP).

- Set a firm shipping date that allows adequate time for the carriers to coordinate the shipment and maintain that shipping date (WVSNF; FRR; WIPP).

- Prepare comprehensive operational checklist to ensure activities leading up to shipment are completed on time (WVSNF).

- Ensure frequent and consistent communication and coordination among all parties involved (TEC 2; WIPP).

- Evaluate prudence of meeting higher safety standards than required by regulation (WVSNF; TEC 2; WIPP). 
- Certain circumstances may merit going beyond regulatory requirements, including first shipments and sensitive communities; however, caution should be taken not to set unreasonable precedents. (TEC 2)

- Work to eliminate excess promises to local jurisdictions that DOE cannot meet. (FRR)

- DOE imposed a significant amount of added requirements on the carriers above and beyond the carriers' normal operations. These requirements are a result of DOE's interactions with the States and Tribes. (WVSNF)

- Minimize the number of requirements imposed on the railroad carriers. This will improve negotiating of contracts and prevent requirements being imposed that cannot be met by the carriers due to federal regulations and union agreements (WVSNF; FRR).

- Areas for re-evaluation - Commitments and accommodations beyond regulatory requirements (curfew, holidays and special events, highway route controlled quantity status for empty shipments, vehicle replacement and servicing, driver standards, etc.). (WIPP)

- Advances in physical and tracking technologies need to be factored into transportation plans (TEC 2).

- Need a timeline of arrival \& departures that is formula based and easy to manage (WVSNF).

- Prepare a Status Center Guide (WVSNF).

- For the status center, consider a full complement of telephones, computers, a large staff, and using a telephone recording device to ensure all messages are captured properly (WVSNF).

- Consistency is needed in information and messages (TEC 2; WIPP).

- DOE support crew - select people proficient in public relations and who perform multidisciplinary functions (WVSNF).

- Multiple shipment campaigns that cover years would greatly benefit in development of a system-wide process for notifying points of contact in the States, Tribes, railroads, and FRA. A secure web-based system that allowed the organizations to update their personnel information, telephone numbers, etc., on an ongoing basis would save an enormous amount of time and effort. (WVSNF)

- Perform safety reviews for the installation and removal of the TRANSCOM equipment (WVSNF).

- Strengthen communications with support personnel aboard the train by using cell phones, satellite telephones, and best technology available. Specify the uses for each type of phone used to communicate with the WCC, local responders, the status center and TRANSCOM (WVSNF; SNF; FRR).

- Work closely and keep in contact with the receiving site (SNF; TEC 3).

- Use locomotive engines that are commonly used in the area, especially for the point of origin to minimize additional interest from locals (i.e., railfans) created by unfamiliar locomotives being in the area (WVSNF).

- Motor carrier drivers need to be fully instructed prior to any shipment regarding the route, escort procedures, unplanned stops, communications, and following directions from DOE dispatch and local law enforcement agencies (CCTWG). 


\section{Plans \& Documents}

- Incorporate elements of successful transportation plans - don't reinvent the wheel (TEC 2).

- All shipments should have transportation plans that describe operational strategies and delineate steps. DOE's transportation plans should be consistent among programs (SNF; CCTWG).

- Transportation plans need to outline the necessary inspections that will take place before, during and after shipments and how participants will meet applicable requirements. It should describe where, who and what will be inspected (tiedowns, casks, etc.). It should describe related policies and plans that complement other required inspections (SNF; WVSNF; WIPP).

- DOE needs to come to resolution on how to handle sensitive information in transportation plans, while still allowing them to be useful (WVSNF).

- The transportation plan should ensure that the security plan is coordinated among the necessary parties (SNF).

- Transportation plans should provide contact lists and describe 1) the type of information to be provided during the notification process; 2) who has the overall responsibility for making the notification; 3 ) the coordination between the carrier, shipper and the receiver site to ensure that necessary notifications are made (SNF; CCTWG).

- Transportation plan should clearly delineate what constitutes a notification; how notifications will be made; and how DOE, State and Tribal authorities and other Federal agencies, if required, will be notified in the event of an emergency (SNF; CCTWG).

- Transportation plan should state what pre-notifications will occur and how they will be transmitted as required by regulations and agreements. Plan should include how DOE intends to keep up with changes of State administrations, including staff turnover (SNF).

- Transportation plans should cover pre-notifications and emergency notifications. (WVSNF).

- DOE Transportation plans should be coordinated with carrier's notification plans (SNF).

- Transportation plan changes from previous revisions should be highlighted for ease in review by States/Tribes. (CCTWG)

- Prepare a package of DOE support crew documentation (to include key documents and instructions such as shipping papers, maps, charts, DOE support crew instructions, survey forms, TRANSCOM plan, railroad release forms, etc.) for use during the shipment. (WVSNF; TEC; WIPP).

- Prepare standard plans (i.e., Emergency Preparedness Coordination Plan, Public Communications Plan) for all DOE material shipments (i.e., SNF, etc.) (WVSNF; SNF)

- Prepare a comprehensive operational contingency plan that includes how States and Tribes will be involved; contingencies for weather and adverse road/track conditions and what provisions will be made in the event of unplanned detours, unscheduled delays, accidents, vehicle breakdown, and threats against the shipment; identify who is responsible for authorizing use of alternate routes and which DOE authority and others need to be notified. If the carrier develops the operational contingency plan, it should receive prior approval from DOE (SNF; WIPP).

- Distribute all documents at the same time to ensure better integration (WVSNF; SNF; CCTWG). 
- The DOE transportation plan and the motor carrier plan need to include some type of contingency actions to be taken by the motor carrier in the event of a delay by the escorts (CCTWG).

- Request that States and Tribes provide a telephone number that is staffed 24 hours/day, 7 days/week to ensure notifications are effectively sent and received with a minimal number of changes (WVSNF).

\section{Routing}

- Routing of shipments should not be disclosed; it should be protected information (WVSNF; SNF).

- Follow standardized approach for all planned route selections. Flexibility is key component of planning (SNF; TEC 2; WIPP).

- Coordinated and integrated planning with representatives from State, Tribal and local governments, and carriers, should be conducted to identify the appropriate route early in the planning process (SNF; WIPP).

- Identify routes early allowing sufficient time for training (TEC 2; WIPP).

\section{Inspections - Rail}

- If railroad equipment is delivered at another location, consider 1) inspection of railroad equipment by FRA inspector in the rail yard where preventive maintenance was performed; 2) make provisions for performing emergency repairs to railcars after delivery (WVSNF).

- Perform thorough receipt inspection of the railcars (other equipment) as early as possible (WVSNF).

- Radiological inspections by multiple agencies cause excessive delay (FRR).

- Standardize the preshipment radiological inspection; conduct it sufficiently in advance of the planned shipment to allow distribution to all involved parties; and use it as the cornerstone of the confirmatory inspections (WVSNF).

- Eliminate the need to plan specific enroute locations for radiological inspections by State and Tribal agencies. Establish a way to address current state and tribal requirements to more efficiently conduct radiological monitoring (WVSNF).

\section{Security}

- All involved parties must understand requirements for safeguarding information. This needs to be included in the transportation plans and discussed during the planning calls (WVSNF; CCTWG; WIPP).

- Security plan should identify all requirements applicable to the shipment. Balance the need to coordinate information with need-to-know (WVSNF; SNF; TEC 1; TEC 2; WIPP).

- The security plan should take into consideration the assessments that have been performed by $\mathrm{DOE}$ and external organizations of possible security threats against shipments, as applicable (SNF).

- Communication of sensitive shipment information should only be provided to designated individuals with need-to-know. Sensitive information should not be left on recording devices (WVSNF; FRR; SNF). 
- Ensure there are consistent security communication policies for disseminating sensitive information effectively. Investigate using secure telephone lines when sensitive information needs to be relayed (WVSNF; WIPP).

- Ensure all parties receiving sensitive and/or Official Use Only (OUO) information know the definition of sensitive information and OUO, and provide guidance on how to disseminate and handle sensitive and OUO materials (WVSNF).

- Communication and security should be evaluated differently for highly visible shipments (TEC 2).

- The receiving site's security office must work with the shipper, NRC and local law enforcement to establish safe parking areas on either side of State borders where escorts are required to hand-off or receive shipments (CCTWG).

- Consider use of Federal Marshals as shipment escorts (WVSNF).

- Balance security with information dissemination - provide the right information to the right people (WVSNF; TEC 2; WIPP).

\section{OUTSOURCING}

\section{General Considerations}

- Prepare checklists for each supplier/contractor and use as living documents to identify activities for which each party is responsible, and to track the status of each activity (SNF; WVSNF; TEC 2).

- Begin outsourcing process early because it often takes longer than expected (WVSNF; TEC 2; WIPP).

Rail

- Award a technical contract and a separate freight contract to the railroads. Distinguish the scope of each and discuss thoroughly each item in the technical contract (WVSNF).

- A minimum of two years should be allocated to negotiate a basic agreement and even longer for complex shipments (WVSNF).

- Negotiation of a system-wide tender rate with key railroad carriers for making SNF shipments over the major routes is highly suggested (WVSNF).

- Clearly understand the operations of railroads to maximize the potential benefits of moving SNF by rail. Rail is significantly different than truck transport (WVSNF).

\section{STAKEHOLDER RELATIONS}

\section{Training}

- Provide training and support for responders, law enforcement and emergency management agencies. Training of first responders has been successful (TEC 2; WIPP).

- Training for shippers, States, Tribes, carriers, etc. should include realistic exercises (TEC 3).

- Provide assistance based on determining incremental risk-based needs (FRR; WIPP).

- Follow-up to ensure responder training funding is used appropriately (TEC 2; WIPP).

- Ensure emergency responders are trained at all levels for the type of shipment being 
planned (TEC 2).

- Training exercises need to be realistic, security sensitive, and should be used as a best practice (TEC 2).

- Coordinate with other Federal agency training programs (TEC 2).

- To mitigate possible conflicts if an alternate route becomes necessary, DOE, States and Tribes should consider broadening the training being provided (TEPP's MERRTT) to include alternate routes. The goal should be to eventually integrate radioactive materials training into general responder training for hazardous materials (WVSNF; FRR; TEC 1 and 2).

- Increase the TEPP's role to prepare for upcoming shipments along existing or new corridors to ensure on-going preparedness of States and Tribes (WVSNF; TEC 1).

- Consistency is needed in information and messages (TEC 2; WIPP).

\section{Stakeholder/Public Expectations}

- All plans (Transportation, Communication, etc.) should be formatted to meet the National Transportation Program's format (easier for States and Tribes to review) (WVSNF).

- Keep information in notifications to States and Tribes to a minimum (i.e., shipment dates, shipment departure, when shipment crosses state and tribal boundaries, etc.) (WVSNF).

- Work through State regional groups and TEPP functions (WVSNF; WIPP).

- Develop and provide resource guides and media packets. Focus on material-specific information, not campaign-specific resource guides (WVSNF; WIPP).

- Establish points-of-contact for DOE, States and Tribes for all DOE transportation issues (TEC 2).

- Properly identify the scope or level of interest in the campaign or shipping schedule, enlisting the assistance of State, Tribal and regional points of contact at the start and throughout the campaign (SNF).

- Make use of existing resources. (SNF).

- Provide accurate information written for the target audience (SNF; WIPP).

- Freely share information with other agencies, States, Tribes and organizations that are helping to plan shipments (SNF; WIPP).

- Stakeholders were prepared for and appropriately informed of the safe and secure transport of the shipment (FRR; WIPP).

- DOE should designate speakers based on the issues, regions, phases (single source), and have technical experts trained to communicate information in reasonable language. (TEC 2)

- DOE should use States, Tribes and local personnel to ensure safe shipping.

Communications should go through trusted local officials including the local fire chief or other local emergency personnel. (TEC 2)

- DOE should identify stakeholders and get them involved in a two-way dialogue. This will dispel rumors and build credibility. DOE needs to ensure that the right mix of planners is involved including radiation workers, public workers, urban planners, etc. Other trusted people include the port authorities, labor unions, and other local emergency personnel. (TEC 2)

- DOE should identify stakeholders and get them involved in a two-way dialogue to help dispel rumors and build credibility (TEC 2; WIPP). 
- Public awareness training greatly turned perceptions to positive. Increase the public understanding of the transport of radioactive materials and proven safety of shipping procedures to lessen public concerns which led to general acceptance of the transport. (FRR; WVSNF; TEC 1, 2, and 3)

\section{Emergency Planning}

- Prepare contingency plan to provide mitigation \& recovery actions for each potential incident. Keep response to incident systematic. Identify who's involved, and who's responsible (WVSNF; SNF; WIPP).

- Freely share information with other agencies and organizations that are helping to plan the shipments (SNF; WIPP).

- Use consistent approach to planning for emergency response. Use TEPP tools (SNF; WIPP).

- Make use of existing resources (SNF).

- Ensure everyone knows who is responsible and who has what responsibilities (TEC 3; FRR; WIPP).

- A point-of-contact for archaeological purposes should be identified in the event of a recovery/cleanup being required on Tribal land (TEC 3).

- Increase the TEPP role as a proactive system to prepare for upcoming shipments along existing or new corridors to ensure on-going preparedness of States and Tribes (WVSNF).

- Prepare a comprehensive operational contingency plan that includes how States and Tribes will be involved; contingencies for weather and adverse road/track conditions and what provisions will be made in the event of unplanned detours, unscheduled delays, accidents, vehicle breakdown, and threats against the shipment; identify who is responsible for authorizing use of alternate routes and which DOE authority and others need to be notified. If the carrier develops the operational contingency plan, it should receive prior approval from DOE. (SNF).

- Establish clear chain of responsibilities (TEC 3; WIPP).

- Have a backup plan in the event the Homeland Security Threat Level changes before a shipment or during a shipment (i.e., contingency plan) (TEC 2).

- Monitor the Internet to maintain cognizance of the information being viewed by rail fans and other members of the public (WVSNF).

- Have backup procedures in the event the TRANSCOM system is down (i.e., contingency plan) (WVSNF; TEC 2; FRR; CCTWG).

- Identify alternate safe parking in the event of weather, accident, etc. situations (i.e., contingency plan) (SNF; WIPP).

- The receiving site's security office must work with the shipper, NRC and local law enforcement to establish safe parking areas on either side of a state border where escorts are required in the state to be entered (CCTWG).

NOTE: The lessons learned contained in this document have been summarized from review of documents identified on page 8 , Reference Key. For electronic copies of these documents, please contact Marsha Keister (marsha.keister@inl.gov) or Kathy McBride (kathryn.mcbride@inl.gov). 